\title{
Distribution of Leishmania major zymodemes in relation to populations of Phlebotomus papatasi sand flies
}

\author{
Omar Hamarsheh
}

\begin{abstract}
Phlebotomus papatasi (Scopoli) (Diptera: Psychodidae) is the main vector of Leishmania major Yakimoff \& Schokhor (Kinetoplastida: Trypanosomatidae), the causative agent of zoonotic cutaneous leishmaniasis in the Old World. Multilocus enzyme electrophoresis (MLEE) was extensively used to type different L. major stocks allover the world. Multilocus microsatellite typing (MLMT) has been recently used to investigate P. papatasi sand flies at population and subpopulation levels. In this article, the association between geographical distribution of L. major zymodemes and the distribution of populations and subpopulations of L. major vector; P. papatasi are discussed.
\end{abstract}

\section{Introduction}

Zoonotic Cutaneous Leishmaniasis (ZCL) is caused by the parasitic protozoan Leishmania major, which is transmitted by the phlebotomine sand fly Phlebotomus papatasi. P. papatasi is also a vector of Leishmania arabica in Saudi Arabia [1,2], and of arboviruses in many countries $[3,4]$. Using various techniques like isoenzyme electrophoresis, polymerase chain reaction (PCR) and sequencing of different genes, L. major had been firmly identified in $P$. papatasi $[5,6]$. Many trypanosomatid infections have been recorded from wild sand flies [7]. However, many of these infections might have been other mammalian Leishmania species, or even lizard Sauroleishmania, as isolation and further characterization was not attempted. In countries north of Iran, much transmission of L. major, L. turanica and L. gerbilli is believed to occur in or near the burrows of the great gerbil Rhombomys opimus [8]. These burrows provide refuges for many sand fly species as well as for mammals and reptiles, making them a high risk habitat for the transmission of parasites to mammals and lizards [9]. In the former USSR, the distribution of L. turanica in rodents coincided with that of the sand flies P. papatasi [10]. The incrimination of a sand fly species as being the vector is complicated, Killick-

Correspondence: ohamarsheh@gmail.com

Department of Biological Sciences, Al-Quds University, P.O. Box 51000, East Jerusalem, Palestine
Kendrick and Ward in 1981 established different grades of certainty; these include, anthropophily and geographic distribution in accord with the disease (Grade 1 and 2). Grade 3 requires that Leishmania be isolated from wild caught flies. Grade 4 establishes development of the parasite in the gut of the suspected vector. Grade 5 demonstrates experimental transmission of Leishmania by bite [11].

To date, there is no vaccine or effective cure for leishmaniasis [12]. It is postulated that successful establishment of the disease in an endemic area is the outcome of a close association between the Leishmania parasite and its natural sand fly vector. This close relationship between the parasite and its corresponding vector may have implications from the epidemiological point of view to the distribution of the disease as well as disease dynamics [13]. Close distribution results in considerable heterogeneity of both vector and parasite and this exemplifies a successful adaptation of a parasite resulting in distinct outcomes of infection and a complex epidemiological pattern. Several studies by leading researchers on sand fly-Leishmania interactions [14-17] proved a fairly selective relationship between Leishmania parasites and its corresponding sand fly vectors, which is typically the result of both ecological and molecular factors. This relationship involves the ability of Leishmania parasites to infect healthy sand flies by successful attachment of Leishmanai parasites to the sand fly midgut. In the case of $L$. major, attachment is provided by the parasite's 
surface lipophosphoglycan (LPG) to the Pp Galectines of the $P$. papatasi midgut proteins [15]. Other pathways existed; studies on mutants in LPG biosynthesis suggested the existence of LPG independent pathway of parasite attachment [18-20], thus, other unknown genes may potentially involve in the attachment relationship. Genetic variability among Leishmania and sand fly populations is crucial to unravel hidden genetic factors controlling the attachment of parasites to the midgut of the $P$. papatasi sand fly and therefore controlling the competence and infectivity of $P$. papatasi sand fly and L. major parasites respectively. To fulfill this long term goal, both $P$. papatasi and L. major were extensively studied and genetically typed in recent years using different molecular markers in a way to understand its systematics as well as population structures. These studies revealed the presence of isolated populations for both $L$. major and P. papatasi in different countries in the Old World [21-23].

Our knowledge about the wide genetic variability and phylogenetic relationships among the different lineages of $L$. major parasites and $P$. papatasi vectors has grown exponentially. This growth of knowledge has been supported by theoretical approaches based on population genetic analysis and the increasing development of molecular biology tools used to identify different genotypes. Genetically, $P$. papatasi is not a polymorphic sand fly. Phylogenetic studies using various molecular markers report a high genetic homogeneity [23,24].The level of genetic variability among L. major is very low and it is considered the least polymorphic Leishmania species [21,25].

Techniques of molecular biology including advancement in sequencing techniques are now becoming feasible and applicable in sand fly research [26-30]. On the other hand, parasite characterization were traditionally and routinely carried out by the French WHO reference laboratory at Montpellier (Laboratoire d'Ecologie Médicale et Pathologie Parasitaire, Faculté de Médecine, Montpellier, France) using multi locus enzyme electrophoresis, the zymodeme (defined as a collection of stocks that have the same isozyme profile [31] ) characterization based on starch gel multilocus enzyme electrophoresis (MLEE) typing. The zymodeme classification become popular over the years by providing a baseline insight into the molecular epidemiology of $L$. major. Since the distribution of zymodemes sometimes limited by geographical boundaries [32-34]. MLEE was very useful for the characterization of L. major parasites, but attempts to use MLEE to genetically differentiate $P$. papatasi populations which were carried out in the past provided no useful genetic information about the structure and distribution of different $P$. papatasi populations [35].
DNA markers such as genomic DNA sequence features and DNA microsatellites are useful for analyzing genetic variations among sand flies [23,36-39]. Mitochondrial DNA sequence polymorphism is very useful for studying differences between closely related species and among populations of the same species from different geographic locations, but it lacks the sensitivity to detect very subtle differences that frequently exist among very recently diverged populations $[26,40]$. The use of multilocus microsatellite analysis based on DNA sequences with short tandem repeat motifs such as (GT) $\mathrm{n}$ [41], demonstrates high variation in the number of repeats seen in individuals from different populations and thus are useful for studying population genetics [42]. Therefore, multilocus microsatellite typing (MLMT) has recently been applied to both $P$. papatasi sand flies and $L$. major parasites, providing additional information about the transmission dynamics of L. major $[21,43]$ as well as the distribution and dispersal of $P$. papatasi [23].

In previous years, MLEE were used extensively to type isolates from various regions in Asia, Africa and Europe. The Laboratoire d'Ecologie Médicale et Pathologie Parasitaire, Faculté de Médecine, Montpellier, France became a reference for typing Leishmania isolates from all over the world. Zymodeme and DNA analysis proceeded in recent years in parallel lines; researchers used other genetic markers to reveal additional diversity within each zymodeme. Different molecular approaches have been used including random amplification of polymorphic DNA (RAPD), kDNA fragment length polymorphisms (schizodemes), karyotype variation, PCR amplicon size polymorphisms, $\mathrm{PCR}$ restriction fragment length polymorphisms (PCR-RFLPs) and comparative DNA sequencing of nuclear and mitochondrial targets [44-47]. In the literature there is much valuable information about the distribution of both $L$. major zymodemes [25] and P. papatasi sand fly populations and subpopulations [23,39]. Recently, a debate has been raised about the possible correlation between the distribution of populations and subpopulations of $P$. papatasi in relation to L. major zymodemes. Therefore, this review aimed to discuss the possible association between the distributions of L. major zymodemes in relation to the distribution of $P$. papatasi populations and subpopulations.

\section{L. major zymodemes versus $P$. papatasi populations}

Globally, two main predominant and widespread zymodemes were reported for L. major, MON 25 and MON 26 [25]. More recently, a correlation between microsatellite markers and geographical origin was evaluated in $P$. papatasi, suggesting MLMT to be effective for population analysis in sand flies [23]. The geographical 


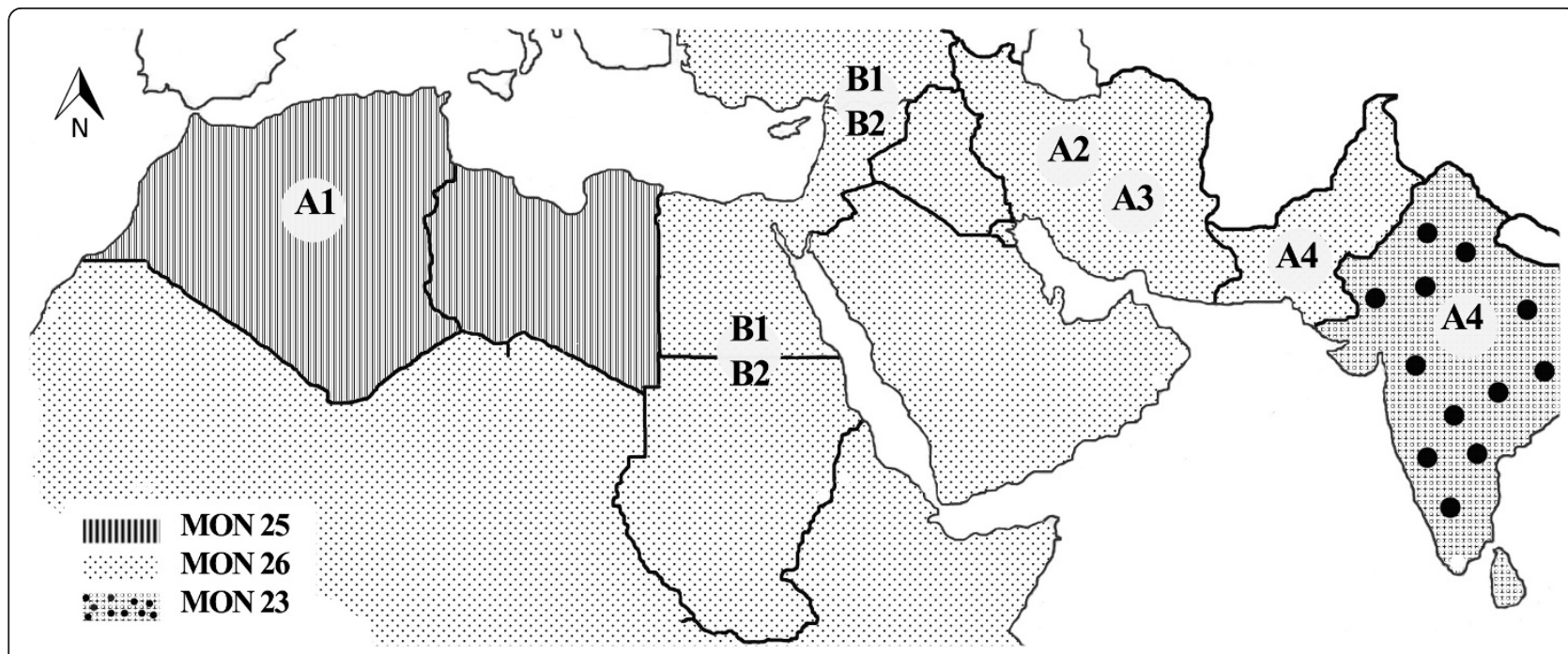

Figure 1 Geographical distribution of $L$. major zymodemes in relation to $P$. papatasi populations and subpopulations. Distribution of the main L. major zymodemes; MON 25, MON 26, MON 23 and MON 26 variants (MON 74, MON 103 and MON 117) in relation to the distribution of $P$. papatasi populations and subpopulations (A1-A4, B1, B2).

distribution of the main L. major zymodemes and populations of $P$. papatasi is shown in Figure 1.

In the east Mediterranean region (i.e., Palestine, Israel, Jordan, Turkey, and Syria), the commonest zymodeme is MON 26 which came from a semi-arid rural area where Psammomys obesus is widespread $[25,48,49]$. In agreement with MLEE, the population structures inferred by microsatellite typing of $P$. papatasi vector in these countries were mixed and restricted to only one population designated as 'B' which is further subdivided into 'B1'and 'B2'substructures without significant geographical distribution [23]. MON 26 is remarkably distributed over a large geographical range extending from Senegal in the west to Kazakhstan and Pakistan in the east. The east Mediterranean region represents small part of this range. Other less prevalent zymodemes include MON 66-68, MON 103 and MON 74 that were found to coexist in Palestinian Territories and Israel, Jordan and Egypt respectively. These less prevalent zymodemes considered as variants from MON 26 which only differ by a single enzyme each $[25,32]$. The L. major zymodeme in Sudan is MON 74, which considered as a variant from MON 26 , and present within the range of MON 26, the same zymodeme was characterized from an L. major infected P. duboscqi sand fly collected from southern Ethiopia [50]. This is in agreement with the population structure of $P$. papatasi in Sudan in which 'B2' subpopulation is prevalent. MON 74 is also existed in southern Egypt, particularly in the areas close to the Sudanese borders; it seems that MON 74 diffused from Middle and Western Africa to Egypt, and probably other countries, where this zymodeme is less prevalent. This scenario is supported by historical information in which migration of people from Africa to the north was moved through Egypt.

The North Maghreb countries Tunisia, Algeria and Morocco share with a unique zymodeme MON 25, although other less prevalent zymodemes do exist; MON 24 in Tunisia and MON 269 in Morocco. The P. papatasi populations in Maghreb countries were exclusively belonging to 'A1' subpopulation [23]. To explain this discrepancy; MON 25 is a uniform zymodeme restricted to the Maghreb countries with high genetic stability. The presence of other less prevalent zymodemes in Maghreb (MON 269 which differs from MON 25 by single enzyme only (PGD)), may correspond to a recent mutation, or post-translational modification of the proteins that allow this slight change and the creation of new zymodemes [51]. The genetic homogeneity associated with the wide distribution of MON 25 suggests the emergence and rapid diffusion of this zymodeme over the whole Maghreb. MON 25 is diffused to the Sahel (Mali) which could possibly be explained by diffusion of the parasite due to human migration and/or to historical climatic changes (humid periods in Sahara) [25,52].

Using MLMT, P. papatasi populations in Iran were substructured in two subpopulations 'A2 and A3' with high population differentiation $[23,53]$. On the other hand mitochondrial and Wolbachia markers for P. papatasi showed little population differentiation between peridomestic sites and gerbil burrows in Isfahan province[37,54], even though the $L$. major parasites were belong to the same zymodeme; MON 26 that isolated from the eastern Middle East. It should be noted; based on isoenzyme 
characterization, L. major zymodeme MON 26 was identified in one infected $P$. papatasi [33] and in one infected $P$. cuacasicus sand flies [55]. This contradicted the population structure results, in which $P$. papatasi typed in this country, belong to two subpopulations (A2-A3) [23]. L. major zymodeme MON 26 has been isolated from both rodents and humans, and no other zymodemes were characterized in Iran [25,56-59]. Therefore, MLEE seems to be limited in detecting variations among $L$. major from Iran probably due to the fact that $L$. major has a limited isoenzyme polymorphism over a wide area in favor of poorly structured populations, or genetic variations were not affected the amino acid sequences in the studied enzymes in MLEE. Previous research documented the presence of genetic variations among different $L$. major strains from different provinces in the country. Using sequences from internal transcribed spacers, variations were manifested in five genotypic groups; $\mathrm{LmA}, \mathrm{LmB}, \mathrm{LmC}, \mathrm{LmD}$ and $\mathrm{LmE}$ [22]. This could be the reason for the existence of new $L$. major endemic areas and increasing cases of cutaneous leishmaniasis which have been reported during recent years in Iran especially from border areas between Iran and Pakistan and between Iran and Afghanistan [60-63].

In India the prevalent zymodeme is MON 23 and $P$. papatasi population structure was depicted exclusively to 'A4'; there is a complete association between the distribution of zymodeme and population structure based on MLMT in this country [23,25]. In Pakistan, P. papatasi populations that originated from Baluchistan province was grouped in 'A4', this subpopulation includes, however, sand flies from India. No clear explanation from the differences between zymodeme distribution of L. major and population structure of $P$. papatasi in Pakistan is available, thus analysis of more sand flies and Leishmania stocks along the Iranian and Pakistani borders is needed. Baluchistan is a mountainous and arid area shared by Iran and Pakistan but divided by borders between the two countries. The prevalent zymodeme in this province is MON 26. This possibly explains that the presence of this zymodeme (MON 26) in this country may have originated from Iran, where MON 26 is widely spread.

\section{Conclusions and research needs}

Among sand flies recorded from the Middle East, only $P$. papatasi was judged to be a proven vector of $L$. major [2]. The wide distribution range of $P$. papatasi is limited to a certain number of populations and subpopulations. This satisfies the wide distribution of L. major in the same range of $P$. papatasi which is also limited to a certain group of main zymodemes like MON 25, MON 26 and MON 23, and to other overlapping less prevalent variants. MON 25 is characterized in $P$. papatasi in Maghreb countries [64], the Middle-East, Saudi
Arabia and Iran, MON 26 [33,65-68] and India, MON 23 [25].

This review provides baseline information about the association of MLMT and MLEE of the P. papatasi vector and L. major parasites. Further research is needed and should be directed toward analyzing more globally distributed parasite strains and sand fly samples using both MLMT and MLEE. Developing new polymorphic microsatellite markers for both $P$. papatasi sand flies and other Leishmania vectors is also essential. Studies and further investments in this field may disclose markers appropriate for population genetics and thus explain the vectorial capacity and parasite infectivity among its structures. Studies emphasizing the correlation between other sand fly species and with its correspondent vectors are very interesting research fields. The information obtained may significantly improve our understanding of the transmission and distribution of Leishmania parasites in relation to their vectors, and could possibly provide more information about sand flyleishmania evolutionary relationships. This would have implications for leishmaniasis intervention and control. To address this long term and promising goal, it would be beneficial to create a public database that makes Leishmania and sand fly microsatellite allele data available worldwide. Finally, there is also a need for the standardization of the microsatellite genotyping techniques including the use of primers and the separation techniques.

\section{Acknowledgements}

The author wish to thank Ahmad Amro for comments on the manuscript.

\section{Competing interests}

The author declares that he has no competing interests.

Received: 8 November 2010 Accepted: 25 January 2011

Published: 25 January 2011

\section{References}

1. Peters W, Elbihari S, Evans DA: Leishmania infecting man and wild animals in Saudi Arabia. 2. Leishmania arabica n. sp. Trans $R$ Soc Trop Med Hyg 1986, 80:497-502.

2. Killick-Kendrick R: Phlebotomine vectors of the leishmaniases: a review. Med Vet Entomol 1990, 4:1-24.

3. Javadian E, Tesh R, Saidi S, Nadim A: Studies on the epidemiology of sand fly fever in Iran. III. Host-feeding patterns of Phlebotomus papatasi in an endemic area of the disease. Am J Trop Med Hyg 1977, 26:294-298.

4. Tesh R, Saidi S, Javadian E, Nadim A: Studies on the epidemiology of sand fly fever in Iran. I. Virus isolates obtained from Phlebotomus. Am J Trop Med Hyg 1977, 26:282-287.

5. Parvizi P, Mauricio I, Aransay AM, Miles MA, Ready PD: First detection of Leishmania major in peridomestic Phlebotomus papatasi from Isfahan province, Iran: comparison of nested PCR of nuclear ITS ribosomal DNA and semi-nested PCR of minicircle kinetoplast DNA. Acta Trop 2005, 93:75-83.

6. Parvizi $P$, Baghban N, Novin EA, Absavaran A: Detection, identification and molecular typing of Leishmania major in Phlebotomus papatasi from a focus of zoonotic cutaneous leishmaniasis in central of Iran. Exp Parasitol 2010, 124:232-237.

7. Kato $H$, Uezato $H$, Sato $H$, Bhutto AM, Soomro FR, Baloch JH, Iwata H, Hashiguchi Y: Natural infection of the sand fly Phlebotomus kazeruni by Trypanosoma species in Pakistan. Parasit Vectors 2010, 3:10. 
8. Parvizi P, Ready PD: Nested PCRs and sequencing of nuclear ITS-rDNA fragments detect three Leishmania species of gerbils in sand flies from Iranian foci of zoonotic cutaneous leishmaniasis. Trop Med Int Health 2008, 13:1159-1171.

9. Perfil'ev PP: Fauna of the U.S.S.R. Diptera Jerusalem: Academy of Sciences of U.S.S.R. Zoological Institute, New Series 93 III. Translated from Russian by Israel Program for Scientific Translations; 1966.

10. Strelkova MV: The isoenzyme identification and pathogenic characteristics of clones of Leishmania major, L. sp. nov. and L. gerbilli. Med Parazitol (Mosk) 1990, 9-13.

11. Killick-Kendrick R, Ward RD: Ecology of Leishmania. Parasitology 1981, 82:143-152.

12. Okwor I, Uzonna J: Vaccines and vaccination strategies against human cutaneous leishmaniasis. Hum Vaccin 2009, 5:291-301.

13. Rogers ME, Bates PA: Leishmania manipulation of sand fly feeding behavior results in enhanced transmission. PLoS Pathog 2007, 3:e91.

14. Kamhawi S: Phlebotomine sand flies and Leishmania parasites: friends or foes? Trends Parasitol 2006, 22:439-445.

15. Kamhawi S, Ramalho-Ortigao M, Pham VM, Kumar S, Lawyer PG, Turco SJ, Barillas-Mury C, Sacks DL, Valenzuela JG: A role for insect galectins in parasite survival. Cell 2004, 119:329-341.

16. Sacks D, Kamhawi S: Molecular aspects of parasite-vector and vector-host interactions in leishmaniasis. Annu Rev Microbiol 2001, 55:453-483.

17. Volf $\mathrm{P}$, Hostomska J, Rohousova I: Molecular crosstalks in Leishmania-sand fly-host relationships. Parasite 2008, 15:237-243.

18. Bates PA: Leishmania sand fly interaction: progress and challenges. Curr Opin Microbiol 2008, 11:340-344.

19. Myskova J, Svobodova M, Beverley SM, Volf P: A lipophosphoglycanindependent development of Leishmania in permissive sand flies. Microbes Infect 2007, 9:317-324.

20. Volf P, Myskova J: Sand flies and Leishmania: specific versus permissive vectors. Trends Parasitol 2007, 23:91-92.

21. Al-Jawabreh A, Diezmann S, Müller M, Wirth T, Schnur LF, Strelkova MV, Kovalenko D, Razakov S, Schwenkenbecher JM, Kuhls K, Schönian G: Identification of geographically distributed sub-populations of Leishmania (Leishmania) major by microsatellite analysis. BMC Evol Biol 2008, 8:183-196.

22. Mahnaz T, Katrin K, Amer AJ, Isabel M, Gabriele S, Safar F, Hossein AM: Leishmania major: genetic heterogeneity of Iranian isolates by singlestrand conformation polymorphism and sequence analysis of ribosomal DNA internal transcribed spacer. Acta Trop 2006, 98:52-58.

23. Hamarsheh $\mathrm{O}$, Presber W, Yaghoobi-Ershadi MR, Amro A, Al-Jawabreh A, Sawalha S, Al-Lahem A, Das ML, Guernaoui S, Seridi N, et al: Population structure and geographical subdivision of the Leishmania major vector Phlebotomus papatasi as revealed by microsatellite variation. Med Vet Entomol 2009, 23:69-77.

24. Depaquit J, Lienard E, Verzeaux-Griffon A, Ferte $H$, Bounamous A, Gantier JC, Hanafi HA, Jacobson RL, Maroli M, Moin-Vaziri V, et al: Molecular homogeneity in diverse geographical populations of Phlebotomus papatasi (Diptera, Psychodidae) inferred from ND4 mtDNA and ITS2 rDNA Epidemiological consequences. Infect Genet Evol 2008, 8:159-170.

25. Pratlong F, Dereure J, Ravel C, Lami P, Balard Y, Serres G, Lanotte G, Rioux JA, Dedet JP: Geographical distribution and epidemiological features of Old World cutaneous leishmaniasis foci, based on the isoenzyme analysis of 1048 strains. Trop Med Int Health 2009, 14:1071-1085.

26. Hamarsheh O, Presber W, Abdeen Z, Sawalha S, Al-Lahem A, Schonian G: Genetic structure of Mediterranean populations of the sand fly Phlebotomus papatasi by mitochondrial cytochrome $b$ haplotype analysis. Med Vet Entomol 2007, 21:270-277.

27. Kato H, Gomez EA, Cáceres AG, Uezato H, Mimori T, Hashiguchi Y: Molecular Epidemiology for Vector Research on Leishmaniasis. Int $J$ Environ Res Public Health 2010, 7:814-826.

28. Depaquit J, Ferte H, Leger N, Killick-Kendrick R, Rioux JA, Killick-Kendrick M, Hanafi HA, Gobert S: Molecular systematics of the phlebotomine sand flies of the subgenus Paraphlebotomus (Diptera, Psychodidae, Phlebotomus) based on ITS2 rDNA sequences. Hypotheses of dispersion and speciation. Insect Mol Biol 2000, 9:293-300.

29. Moin-Vaziri V, Depaquit J, Yaghoobi-Ershadi MR, Oshaghi MA, Derakhshandeh-Peykar P, Ferte H, Kaltenbach M, Bargues MD, Leger N, Nadim A: Intraspecific variation within Phlebotomus sergenti Parrot (1917)
(Diptera: Psychodidae) based on mtDNA sequences in Islamic Republic of Iran. Acta Trop 2007, 102:29-37.

30. Ready PD, Day JC, Souza AA, Rangel EF, Davies CR: Mitochondrial DNA characterization of populations of Lutzomyia whitmani (Diptera: Psychodidae) incriminated in the peridomestic and selvatic transmission of leishmania species in Brazil. Bull Entomol Res 1997, 87:187-195.

31. Godfrey DG, Kilgour V: Enzyme electrophoresis in characterizing the causative organism of Gambian trypanosomiasis. Trans $R$ Soc Trop Med Hyg 1976, 70:219-224.

32. Belazzoug S, Ammar-Khodja A, Pratlong F, Rioux JA: Leishmania major MON-117, an agent of cutaneous leishmaniasis in Mauritania]. Ann Parasitol Hum Comp 1992, 67:62.

33. Yaghoobi-Ershadi MR, Javadian E, Tahvildare-Bidruni GH: Leishmania major MON-26 isolated from naturally infected Phlebotomus papatasi (Diptera: Psychodidae) in Isfahan Province, Iran. Acta Trop 1995, 59:279-282.

34. Harrat Z, Pratlong F, Benikhlef R, Lami P, Belkaid M, Dedet JP: Leishmania major MON-74 as a causative agent of cutaneous leishmaniasis in Burkina Faso. Trans R Soc Trop Med Hyg 1998, 92:355.

35. Kassem HA, Fryauff DJ, Shehata MG, el Sawaf BM: Enzyme polymorphism and genetic variability of one colonized and several field populations of Phlebotomus papatasi (Diptera: Psychodidae). J Med Entomol 1993, 30:407-413.

36. Aransay AM, Malarky G, Ready PD: Isolation (with enrichment) and characterization of trinucleotide microsatellites from Phlebotomus perniciosus, a vector of Leishmania infantum. Mol Ecol Notes 2001, 1:176-178.

37. Parvizi P, Benlarbi M, Ready PD: Mitochondrial and Wolbachia markers for the sand fly Phlebotomus papatasi: little population differentiation between peridomestic sites and gerbil burrows in Isfahan province, Iran. Med Vet Entomol 2003, 17:351-362.

38. Aransay AM, Ready PD, Morillas-Marquez F: Population differentiation of Phlebotomus perniciosus in Spain following postglacial dispersal. Heredity 2003, 90:316-325.

39. Hamarsheh O, Presber W, Abdeen Z, Sawalha S, Al-Lahem A, Schoenian G: Isolation and characterization of microsatellite loci in the sand fly Phlebotomus papatasi (Diptera: Psychodidae). Mol Ecol Notes 2006, 6:826-828.

40. Anderson JM, Lai JE, Dotson EM, Cordon-Rosales C, Ponce C, Norris DE, Beard CB: Identification and characterization of microsatellite markers in the Chagas disease vector Triatoma dimidiata. Infect Genet Evol 2002, 1:243-248.

41. Rongnoparut $P$, Yaicharoen S, Sirichotpakorn N, Rattanarithikul R, Lanzaro GC, Linthicum KJ: Microsatellite polymorphism in Anopheles maculatus, a malaria vector in Thailand. Am J Trop Med Hyg 1996, 55:589-594.

42. Tautz D, Schlotterer : Simple sequences. Curr Opin Genet Dev 1994, 4:832-837

43. Schonian G, Mauricio I, Gramiccia M, Canavate C, Boelaert M, Dujardin JC: Leishmaniases in the Mediterranean in the era of molecular epidemiology. Trends Parasitol 2008, 24:135-142.

44. Elfari M, Schnur LF, Strelkova MV, Eisenberger CL, Jacobson RL, Greenblatt CL, Presber W, Schonian G: Genetic and biological diversity among populations of Leishmania major from Central Asia, the Middle East and Africa. Microbes Infect 2005, 7:93-103.

45. Asato Y, Oshiro M, Myint CK, Yamamoto Y, Kato H, Marco JD, Mimori T, Gomez EA, Hashiguchi $Y$, Uezato H: Phylogenic analysis of the genus Leishmania by cytochrome b gene sequencing. Exp Parasitol 2009, 121:352-361.

46. Breniere SF, Telleria J, Bosseno MF, Buitrago R, Bastrenta B, Cuny G, Banuls AL, Brewster S, Barker DC: Polymerase chain reaction-based identification of New World Leishmania species complexes by specific kDNA probes. Acta Trop 1999, 73:283-293.

47. Kumar R, Ansari NA, Avninder S, Ramesh V, Salotra P: Cutaneous leishmaniasis in Nepal: Leishmania major as a cause. Trans $R$ Soc Trop Med Hyg 2008, 102:202-203.

48. Rioux JA, Lanotte G, Serres E, Pratlong F, Bastien P, Perieres J: Taxonomy of Leishmania. Use of isoenzymes. Suggestions for a new classification. Ann Parasitol Hum Comp 1990, 65:111-125.

49. Nimri L, Soubani R, Gramiccia M: Leishmania species and zymodemes isolated from endemic areas of cutaneous leishmaniasis in Jordan. Kinetoplastid Biol Dis 2002, 1:7. 
50. Gebre-Michael T, Pratlong F, Lane RP: Phlebotomus (Phlebotomus) duboscqi (Diptera: Phlebotominae), naturally infected with Leishmania major in southern Ethiopia. Trans R Soc Trop Med Hyg 1993, 87:10-11.

51. Mauricio IL, Yeo M, Baghaei M, Doto D, Pratlong F, Zemanova E, Dedet JP, Lukes J, Miles MA: Towards multilocus sequence typing of the Leishmania donovani complex: resolving genotypes and haplotypes for five polymorphic metabolic enzymes (ASAT, GPI, NH1, NH2, PGD). Int J Parasitol 2006, 36:757-769.

52. Maazoun R, Pratlong F, Lanotte G, Rioux J: Le complexe Leishmania major. A propos de l'analyse numerique de 35 souches identifie'es par la methode enzymatique. In Leishmania Taxonomie et phylogene'se Applications e'coepidemiologiques IMEEE. Edited by: Rioux J. Montpellier, France; 1986:119-128.

53. Hamarsheh O, Presber W, Al-Jawabreh A, Abdeen Z, Amro A, Schonian G: Molecular markers for Phlebotomus papatasi (Diptera: Psychodidae) and their usefulness for population genetic analysis. Trans $R$ Soc Trop Med Hyg 2009, 103:1085-1086.

54. Parvizi P, Ready PD: Molecular investigation of the population differentiation of Phlebotomus papatasi, important vector of Leishmania major, in different habitats and regions of Iran. Iran Biomed J 2006, 10:69-77.

55. Yaghoobi-Ershadi MR, Javadian E, Tahvildare-Bidruni GH: The isolation of Leishmania major from Phlebotomus (Paraphlebotomus) caucasicus, in Isfahan province, Islamic Republic of Iran. Trans R Soc Trop Med Hyg 1994, 88:518-519.

56. Yaghoobi-Ershadi MR, Akhavan AA, Mohebali M: Meriones libycus and Rhombomys opimus (Rodentia: Gerbillidae) are the main reservoir hosts in a new focus of zoonotic cutaneous leishmaniasis in Iran. Trans $R$ Soc Trop Med Hyg 1996, 90:503-504.

57. Akhavan AA, Yaghoobi-Ershadi MR, Mohebali M: Abstracts: Epidemiology of cutaneous leishmaniasis (human infection) in Badrood district, Natanz County. the First Congress on Medical Entomology; Jun 13-15; Tehran. Pasteur Institute of Iran, School of Public Health, Tehran University of Medical Sciences 1998, 17-18.

58. Yaghoobi-Ershadi MR, Hanafi-Bojd AA, Akhavan AA, Zahrai-Ramazani AR, Mohebali M: Epidemiological study in a new focus of cutaneous leishmaniosis due to Leishmania major in Ardestan town, central Iran. Acta Trop 2001, 79:115-121.

59. Yaghoobi-Ershadi MRAAA, Mohebali M: Monthly variation of Leishmania major MON-26 infection rates in Phlebotomus papatasi (Diptera: Psychodidae) from rodent burrows in Badrood area of Iran. Iranian J Arthropod-Borne Dis 2001, 15:175-178.

60. Marco JD, Bhutto AM, Soomro FR, Baloch JH, Barroso PA, Kato H, Uezato H, Katakura K, Korenaga M, Nonaka S, Hashiguchi Y: Multilocus enzyme electrophoresis and cytochrome $B$ gene sequencing-based identification of Leishmania isolates from different foci of cutaneous leishmaniasis in Pakistan. Am J Trop Med Hyg 2006, 75:261-266.

61. Fazaeli A, Fouladi B, Sharifi I: Emergence of cutaneous leishmaniasis in a border area at south-east of Iran: an epidemiological survey. J Vector Borne Dis 2009, 46:36-42.

62. Bhutto AM, Soomro FR, Baloch JH, Matsumoto J, Uezato H, Hashiguchi Y, Katakura K: Cutaneous leishmaniasis caused by Leishmania (L.) major infection in Sindh province, Pakistan. Acta Trop 2009.

63. Myint CK, Asato Y, Yamamoto Y, Kato H, Bhutto AM, Soomro FR, Memon MZ, Matsumoto J, Marco JD, Oshiro M, et al: Polymorphisms of cytochrome $b$ gene in Leishmania parasites and their relation to types of cutaneous leishmaniasis lesions in Pakistan. J Dermatol 2008, 35:76-85.

64. Harrat Z, Pratlong F, Belazzoug S, Dereure J, Deniau M, Rioux JA, Belkaid M, Dedet JP: Leishmania infantum and L. major in Algeria. Trans R Soc Trop Med Hyg 1996, 90:625-629.

65. Killick-Kendrick R, Leaney AJ, Peters W, Rioux JA, Bray RS: Zoonotic cutaneous leishmaniasis in Saudi Arabia: the incrimination of Phlebotomus papatasi as the vector in the Al-Hassa oasis. Trans $R$ Soc Trop Med Hyg 1985, 79:252-255.

66. Azizi K, Rassi Y, Javadian E, Motazedian MH, Asgari Q, Yaghoobi-Ershadi MR: First detection of Leishmania infantum in Phlebotomus (Larroussius) major (Diptera: Psychodidae) from Iran. J Med Entomol 2008, 45:726-731.

67. Rioux JA, Dereure J, Khiami A, Pratlong F, Sirdar K, Lambert M: Ecoepidemiology of leishmaniasis in Syria. 1. Leishmania major Yakimoff and Schokhor (Kinetoplastida-Trypanosomatidae) infestation of
Psammomys obesus Cretzschmar (Rodentia-Gerbillidae). Ann Parasitol Hum Comp 1990, 65:203-207.

68. Peters W, Elbihari S, Liu C, Le Blancq SM, Evans DA, Killick-Kendrick R, Smith V, Baldwin Cl: Leishmania infecting man and wild animals in Saudi Arabia. 1. General survey. Trans R Soc Trop Med Hyg 1985, 79:831-839.

\section{doi:10.1186/1756-3305-4-9}

Cite this article as: Hamarsheh: Distribution of Leishmania major zymodemes in relation to populations of Phlebotomus papatasi sand flies. Parasites \& Vectors 2011 4:9.

\section{Submit your next manuscript to BioMed Central and take full advantage of:}

- Convenient online submission

- Thorough peer review

- No space constraints or color figure charges

- Immediate publication on acceptance

- Inclusion in PubMed, CAS, Scopus and Google Scholar

- Research which is freely available for redistribution

Submit your manuscript at www.biomedcentral.com/submit
Biomed Central 